\title{
SGLT2 inhibition slows tumor growth in mice by reversing hyperinsulinemia
}

\author{
Ali R. Nasiri ${ }^{1}$, Marcos R. Rodrigues ${ }^{1,3}$, Zongyu Li ${ }^{1,2}$, Brooks P. Leitner ${ }^{1,2}$ and Rachel J. Perry ${ }^{1,2^{*}}$ (i)
}

\begin{abstract}
Background: Obesity confers an increased risk and accelerates the progression of multiple tumor types in rodents and humans, including both breast and colon cancer. Because sustained weight loss is rarely achieved, therapeutic approaches to slow or prevent obesity-associated cancer development have been limited, and mechanistic insights as to the obesity-cancer connection have been lacking.

Methods: E0771 breast tumors and MC38 colon tumors were treated in vivo in mice and in vitro with two mechanistically different insulin-lowering agents, a controlled-release mitochondrial protonophore (CRMP) and sodium-glucose cotransporter-2 (SGLT2) inhibitors, and tumor growth and glucose metabolism were assessed. Groups were compared by ANOVA with Bonferroni's multiple comparisons test.

Results: Dapagliflozin slows tumor growth in two mouse models (E0771 breast cancer and MC38 colon adenocarcinoma) of obesity-associated cancers in vivo, and a mechanistically different insulin-lowering agent, CRMP, also slowed breast tumor growth through its effect to reverse hyperinsulinemia. In both models and with both agents, tumor glucose uptake and oxidation were not constitutively high, but were hormone-responsive. Restoration of hyperinsulinemia by subcutaneous insulin infusion abrogated the effects of both dapagliflozin and CRMP to slow tumor growth.

Conclusions: Taken together, these data demonstrate that hyperinsulinemia per se promotes both breast and colon cancer progression in obese mice, and highlight SGLT2 inhibitors as a clinically available means of slowing obesity-associated tumor growth due to their glucose- and insulin-lowering effects.
\end{abstract}

Keywords: Tumor metabolism, Obesity, Insulin, Glucose

\section{Background}

Approximately $5 \%$ of all cancers in men and $~ 10 \%$ of all cancers in women are attributable at least in part to obesity [1], with certain tumor types exhibiting an even stronger relationship between excess weight and cancer risk. Among these are breast [2-4] and colon cancer [2, $4,5]$, in which obesity promotes tumor appearance, progression, and metastasis in rodent models and in human patients. Hyperinsulinemia, which occurs as a consequence of lipid-induced insulin resistance and may also hasten its progression, is one of many putative links that may explain the association between obesity and cancer:

\footnotetext{
* Correspondence: rachel.perry@yale.edu

'Department of Internal Medicine, School of Medicine, Yale University, PO Box 208020, TAC S269, New Haven, CT 06520, USA

2Department of Cellular \& Molecular Physiology, School of Medicine Yale

University, PO Box 208020, TAC S269, New Haven, CT 06520, USA

Full list of author information is available at the end of the article
}

insulin promotes tumor cell division in vitro [6-10], and plasma insulin concentrations are independently correlated with an increased risk and accelerated progression of both breast [11-15] and colon cancer [16-20]. Interfering with insulin signaling may slow tumor growth [21], while activation of the insulin receptor may promote tumor progression $[22,23]$ in murine models, although there have also been publications demonstrating the absence of an effect of insulin on tumor growth [24]. In humans with type 2 diabetes, exogenous insulin treatment has been linked to an increased risk of developing breast cancer [25-27] and poorer breast cancer outcomes [28-30], although the impact of exogenous insulin on tumor progression is debatable: recent metaanalyses failed to detect an impact of insulin treatment on breast cancer incidence [31-33]. The inconsistent data regarding the impact of exogenous insulin 
treatment on breast cancer risk may be attributable to the fact that exogenous insulin treatment is designed to restore normal circulating insulin concentrations in those with insufficient $\beta$-cell function; thus, it likely does not create hyperinsulinemia in most cases. Even so, the growing body of epidemiologic evidence for an association between insulin and cancer risk and progression begs the question of what explains the potential mechanistic link between obesity, hyperinsulinemia, and cancer.

The ability of insulin to stimulate tumor cell proliferation is likely multifactorial and has been attributed to stimulation of DNA replication and cell cycle progression, potentially by activation of the PI3K/Akt/FOXO1 signaling pathway, increased accumulation of DNA damage, and increases in glucose uptake and/or oxidation. Consistent with the latter mechanism, we have recently shown that insulin's ability to promote glucose uptake and oxidation in vitro constitutes a metabolic signature of obesity-associated tumor types [6], suggesting that insulin-lowering therapies may be an attractive approach to slow obesity-associated tumor growth, thereby prolonging the window during which curative therapies may be possible.

To that end, we have recently demonstrated that mitochondrial uncoupling with a controlled-release mitochondrial protonophore (CRMP) both prevents and reverses insulin resistance and, as a result, hyperinsulinemia by correcting non-alcoholic fatty liver disease (NAFLD) [34], and that the reversal of hyperinsulinemia slows tumor growth in two mouse models of colon cancer, MC38 tumor-bearing and $\mathrm{Apc}^{\mathrm{Min}+/-}$ mice [35]. Because uncoupling is not yet an approved pharmacologic strategy to treat NAFLD, it is of great interest to investigate the potential for other agents to reverse obesity-associated insulin resistance, hyperinsulinemia, and accelerated tumor growth. Metformin also slows colon cancer growth in rodents [36-38] in an insulin-dependent manner [35] and may modestly reduce colon cancer incidence in diabetic humans $[39,40]$. However, safety concerns exist: metformin can cause undesirable gastrointestinal side effects and is contraindicated in those with limited renal function, as it can cause lactic acidosis. Therefore, there is a strong need to investigate alternative insulin-lowering therapies as a potential adjunct in those with obesity-associated tumors.

SGLT2 inhibitors have recently been investigated as a potential anti-cancer therapy and have been shown to induce apoptosis or inhibit proliferation of breast cancer [41, 42], renal cell carcinoma [43], and hepatocellular carcinoma [44] cells at high concentrations in vitro. In vivo studies in rodents treated with SGLT2 inhibitors have also been promising, if limited: canagliflozin lowered tumor burden in mice with hepatocellular [44-46], lung [47], and renal cell carcinoma [43] in vivo. However, the mechanism by which this occurs-and specifically the possible role of alterations in systemic glucose metabolism and potential ability of changes in plasma insulin concentrations to mediate differences in tumor glucose metabolism-has not been explored in obesityassociated tumor types. Here, we examine the impact of SGLT2 inhibition with dapagliflozin on tumor growth in mouse models of obesity-associated cancers: colon adenocarcinoma (MC38 tumors) and triple-negative breast cancer (E0771 tumors), two commonly used murine cancer models whose driver mutations remain under debate and are likely multifactorial, but which robustly express the insulin receptor $[6,36,48,49]$, and demonstrate that dapagliflozin slows tumor growth in both models. This effect is not due to increases in ketosis or to a direct effect on tumor cell division, but rather is mediated by the reversal of hyperinsulinemia, resulting in reductions in tumor glucose uptake and oxidation. Similarly CRMP slows E0771 tumor growth, similar to its effect to slow colon tumor growth [35], by reversing hyperinsulinemia and insulin-dependent increases in tumor glucose uptake and oxidation, without any direct effect to alter tumor cell metabolism or division. Taken together, these data implicate hyperinsulinemia as a key pathogenic factor in the progression of both breast and colon cancer in two mouse models and identify SGLT2 inhibition as a potential means of slowing obesityassociated cancer progression in vivo.

\section{Methods}

Cells

E0771 cells were obtained from $\mathrm{CH} 3$ Biosystems (Amherst, NY) and cultured in the manufacturer's recommended media: RPMI 1640 supplemented with $10 \mathrm{mM}$ HEPES, 10\% FBS, and antimicrobials (100 U/ $\mathrm{mL}$ penicillin $/ 100 \mu \mathrm{g} / \mathrm{mL}$ streptomycin $/ 250 \mu \mathrm{g} / \mathrm{mL}$ amphotericin). MC38 cells were obtained from Kerafast (Boston, MA) and cultured in the manufacturer's recommended media: DMEM containing $25 \mathrm{mM}$ glucose, $2 \mathrm{mM}$ glutamine, $0.1 \mathrm{mM}$ nonessential amino acids, $1 \mathrm{mM}$ sodium pyruvate, $10 \mathrm{mM}$ HEPES, $10 \%$ FBS, and antimicrobials $(100 \mathrm{U} / \mathrm{mL}$ penicillin/100 $\mu \mathrm{g} /$ $\mathrm{mL}$ streptomycin $/ 250 \mu \mathrm{g} / \mathrm{mL}$ amphotericin). Neither cell line was authenticated in our laboratory, but all cells were used within 10 passages of obtaining them commercially. Cells were cultured in a $37{ }^{\circ} \mathrm{C}$ humidified incubator and split as needed (2-3x weekly). In vitro cell division was measured by incubating $1 \times$ $10^{5}$ E0771 cells or $5 \times 10^{4}$ MC38 cells in the agents noted for 2 days (or vehicle, the media described above). Forty-eight hours after plating, cells were washed and trypsinized, and live cells were counted by a blinded investigator $48 \mathrm{~h}$ later. 


\section{Mice}

All animal studies were approved by the Yale University Institutional Animal Care and Use committee. Because E0771 cells are a model of breast cancer that does not express the estrogen or progesterone receptors, and because female mice are protected from obesity-associated insulin resistance [50,51], male mice were used in all studies. C57bl/6J mice were obtained from Jackson Laboratories at 6-8 weeks of age and after 1 week of acclimation, during which time they were fed regular chow (Envigo 2018S, Huntington, Cambridgeshire, UK), and mice were injected with tumor cells $\left(2 \times 10^{5}\right.$ MC38 cells or $5 \times 10^{5}$ E0771 cells). On the day of injection, treatment with high fat diet (Research Diets D12492, New Brunswick, NJ; $60 \%$ kcal from fat, $20 \%$ from protein, $20 \%$ from carbohydrate) or the same HFD-containing CRMP (7 mg CRMP per gram of diet, with an approximate dose of $12 \mathrm{mg}$ active DNP per kilogram of body weight per day). In the insulin replacement studies, three insulin-containing pellets (LinBit) were implanted subcutaneously on the day of tumor injection. Mice treated with dapagliflozin were given drinking water containing $0.01 \mathrm{mg} / \mathrm{mL}$ dapagliflozin (Sigma, St. Louis, MO; approximate dose $2.5 \mathrm{mg} / \mathrm{kg}$ per day), and those treated with metformin were given drinking water containing $33 \mathrm{mg} / \mathrm{mL}$ metformin (Sigma; approximate dose $200 \mathrm{mg} /$ $\mathrm{kg}$ per day). In the $\beta$-OHB supplementation study, sodium $\beta$-OHB (Sigma) was provided at a concentration of $1 \mathrm{mM}$ (approximate dose: $4 \mathrm{mmol} / \mathrm{kg} /$ day).

Tumor size was measured weekly using calipers in duplicate by blinded investigators, with tumors assumed to be spherical for calculation of volume based on the measured diameter. Energetics, food, and water intake were measured using the Columbus Instruments Comprehensive Lab Animal Monitoring System (CLAMS; Columbus, OH) during the first week after tumor implantation. Body composition (lean and fat mass) were examined by nuclear magnetic resonance spectroscopy (Bruker minispec; Billerica, MA). Mice were sacrificed 3-4 weeks after tumor implantation, or when tumor size exceeded $2000 \mathrm{~mm}^{3}$. One week prior to tracer studies, mice underwent surgery to place catheters in the right jugular vein, which were then advanced into the right atrium. After recovery of their pre-surgical body weight and following a 5-h fast, mice underwent tracer studies as described below. Mice were sacrificed at the end of the tracer studies using IV pentobarbital. Tumor, liver, and skeletal muscle (gastrocnemius) were harvested in $\mathrm{N}_{2}$ cooled freeze clamps and stored at $-80{ }^{\circ} \mathrm{C}$ to await further analysis. In the oral glucose tolerance tests (OGTT), mice were gavaged with $1 \mathrm{~g} / \mathrm{kg}$ dextrose, and a blood sample was taken from the tail vein $0 \mathrm{~min}$ (no gavage), 15, 30, 60, or $120 \mathrm{~min}$ afterward. The mouse was sacrificed with isoflurane anesthesia immediately after obtaining the blood sample, and tumors were isolated.

\section{Assessment of tumor glucose uptake and oxidation}

Tumor glucose uptake and $V_{\mathrm{PDH}} / V_{\mathrm{CS}}$ were measured ex vivo after a 6 -h fast following a steady-state infusion of [ $\mathrm{U}_{-}{ }^{13} \mathrm{C}_{6}$ ] glucose $(1 \mathrm{mg} / \mathrm{kg} / \mathrm{min}$ following a 5 -min $3 \mathrm{X}$ prime) and a bolus injection of $\left[1-{ }^{14} \mathrm{C}\right] 2$-deoxy-D-glucose [35]. Briefly, $V_{\mathrm{PDH}} / V_{\mathrm{CS}}$ was measured in vivo and in vitro as the ratio of $\left[4,5-{ }^{13} C_{2}\right]$ glutamate $/\left[{ }^{13} C_{3}\right]$ alanine, with glutamate enrichment measured by LC-MS/ MS and alanine enrichment by GC/MS. To measure $V_{\mathrm{PDH}} / V_{\mathrm{CS}}$ in vitro, we incubated $1 \times 10^{5} \mathrm{MC} 38$ cells or $2 \times 10^{5}$ E0771 cells in a 6-well plate for $120 \mathrm{~min}$ in the manufacturer's recommended media, described above, modified to supply physiological concentrations of glucose (5 mM [U- ${ }^{13} \mathrm{C}_{6}$ ] glucose), and physiological fatty acids ( $1 \mathrm{mM}$ potassium palmitate). After $120 \mathrm{~min}, 1 \mathrm{~mL}$ $50 \%$ methanol was added, and cells were scraped, transferred to a $1.5 \mathrm{~mL}$ Eppendorf tube, centrifuged, and processed to measure $V_{\mathrm{PDH}} / V_{\mathrm{CS}}$ as described above. Of note, we have previously demonstrated that physiologic concentrations of glutamine do not significantly confound the measurement of this ratio [6]. Where indicated, insulin, dapagliflozin, canagliflozin (Sigma), DNP (Sigma), or $\beta-O H B$ (Sigma) were added at the concentrations specified. To measure glucose uptake in vitro, $\left[{ }^{14} \mathrm{C}\right]$ 2-deoxyglucose $(0.1 \mu \mathrm{Ci})$ was added to cells $(2 \times$ $10^{5}$ E0771 cells or $1 \times 10^{5}$ MC38 cells) in media described above. Thirty minutes later, cells were washed three times in warmed PBS, and scraped, collected in a scintillation vial, and $\left[{ }^{14} \mathrm{C}\right]$ specific activity determined using a scintillation counter. The rate of glucose uptake was calculated assuming a constant rate of glucose uptake over the 30-min incubation period.

\section{Biochemical analysis}

Plasma and urine glucose concentrations were measured using the YSI Glucose Analyzer. Plasma insulin was measured by RIA by the Yale Diabetes Research Center, or (OGTT samples only) by ELISA (Mercodia, Uppsala, Sweden), and plasma $\beta$-OHB by GC/MS, using the sample preparation method we have described [52] after spiking plasma samples with a $1-\mathrm{mM}\left[{ }^{13} \mathrm{C}_{4}\right] \quad \beta-\mathrm{OHB}$ standard. Tumor DNP concentrations were assessed by LC-MS/MS [53]. Tumor Akt pSer473 phosphorylation and total Akt expression, pS70 S6K pThr389 phosphorylation, and total S70 S6K expression were assessed by western blot using antibodies from Cell Signaling (cata$\log$ numbers 9271, 2920, 9206, and 9202, respectively).

\section{Statistical analysis}

GraphPad Prism 7.0 was used for statistical analysis. Two groups were compared by the two-tailed unpaired Student's $t$ test, and three or more groups by ANOVA with Bonferroni's multiple comparisons test, after 
verifying that the data met the assumptions of the statistical test employed. Data are presented as the mean \pm S.E.M.

\section{Results}

Dapagliflozin slows E0771 tumor growth in obese mice in an insulin-dependent manner

To examine the potential utility of dapagliflozin as an anti-tumor agent in vivo, we treated obese mice with dapagliflozin in drinking water beginning on the day of
E0771 tumor implantation. Not surprisingly, dapagliflozin caused glycosuria, but did not affect energy expenditure or caloric intake, measured during the first week of treatment before the groups of mice diverged in body weight (Fig. 1a, Additional file 1: Figure S1A-J). As expected, water intake increased in the dapagliflozintreated group as a compensatory mechanism to avoid dehydration, and a small (1\%), physiologically insignificant increase in respiratory exchange ratio was also observed. However, 3 weeks later, sustained glucose

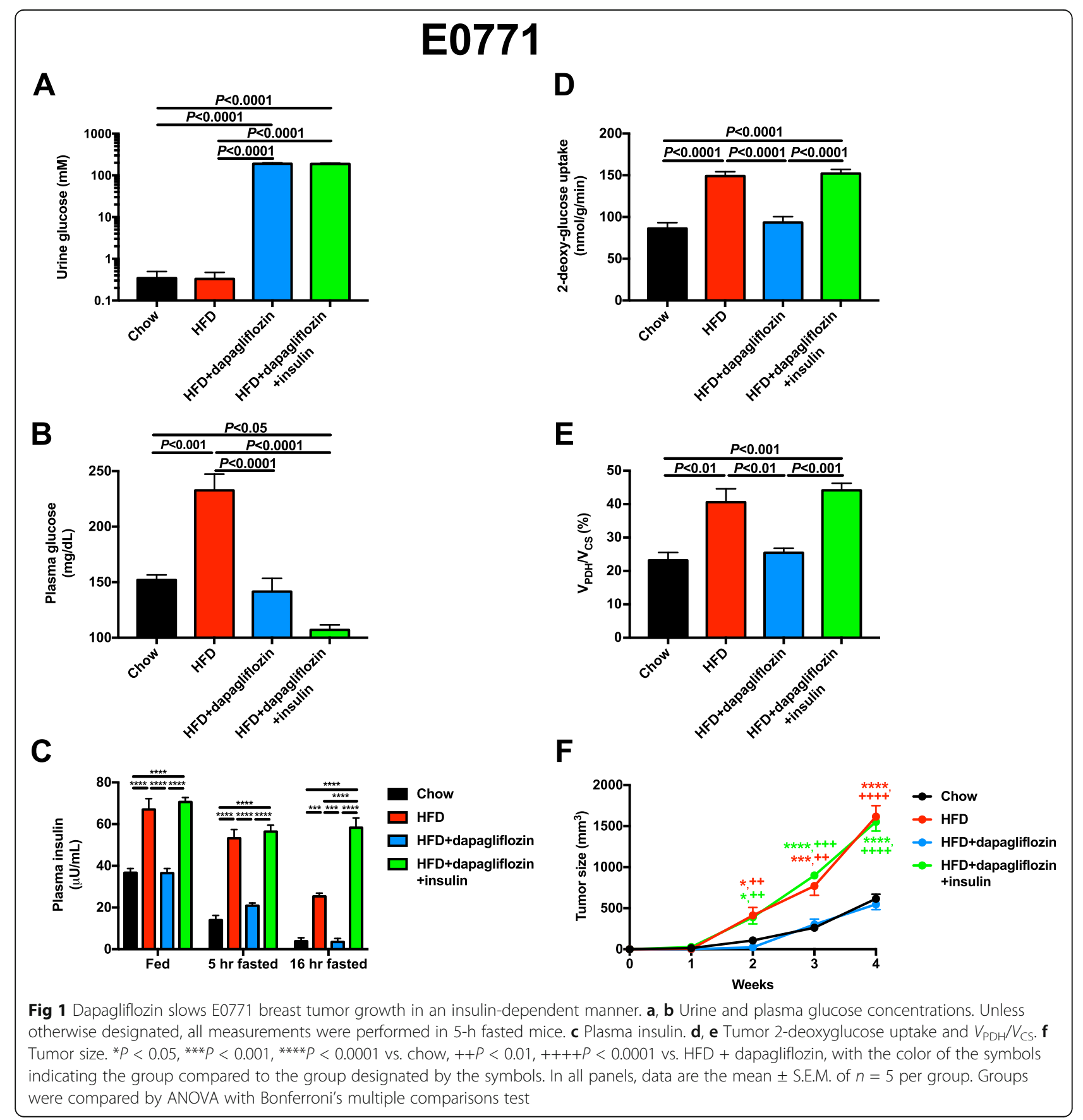


wasting in urine was associated with reductions in body weight and fat mass in high-fat fed mice (Additional file 1: Figure S1K-L). SGLT2 inhibition lowered plasma glucose concentrations in 5 -h fasted mice by $80 \mathrm{mg} / \mathrm{dL}$ and reduced plasma insulin concentrations in fed, 5-h fasted, and 16-h fasted mice (Fig. 1b, c), in contrast to metformin, which lowered plasma insulin only after a prolonged fast (Additional file 1: Figure S1M). To examine the impact of the reduction in plasma insulin on tumor growth and metabolism, we infused insulin subcutaneously to match plasma insulin concentrations in 5-h fasted dapagliflozin-treated mice to those measured in untreated HFD controls. E0771 tumor glucose metabolism was insulin-responsive: glucose uptake and oxidation were increased in tumors of HFD fed, hyperinsulinemic mice but normalized with dapagliflozin treatment; however, restoring hyperinsulinemia via subcutaneous insulin infusion increased tumor glucose uptake and oxidation to rates observed in HFD control mice. Hyperinsulinemia had a profound effect on tumor growth rates: 4 weeks after tumor implantation, E0771 tumors were $1000 \mathrm{~mm}^{3}$ larger in HFD mice than lean controls. However, dapagliflozin treatment reduced rates of tumor growth such that tumor growth in dapagliflozin-treated mice mimicked that of chow fed animals. This effect was insulin-mediated: restoring hyperinsulinemia increased tumor growth rates in dapagliflozin-treated mice to those measured in obese HFD mice.

Next, we aimed to examine whether the ability of dapagliflozin to slow E0771 tumor growth was a cellautonomous effect. The maximum daily dose of dapagliflozin is $10 \mathrm{mg}$ per day in humans; this dose results in a peak dapagliflozin concentration of less than $0.4 \mu \mathrm{M}$ [54]. Ten-fold higher dapagliflozin concentrations had no impact on E0771 tumor glucose uptake or oxidation, nor did this dose of dapagliflozin alter cell division in vitro (Fig. 2a-c); however, 10,000-fold higher, suprapharmacologic dapagliflozin concentrations did reduce glucose uptake and oxidation, associated with slower E0771 cell division in vitro. In contrast, canagliflozin showed a dose-dependent effect to reduce tumor glucose uptake and oxidation and to suppress tumor cell division at pharmacologically relevant doses [55] (Fig. 2a-c). These data indicate that SGLT2 inhibitors may have some cell-autonomous effect to slow tumor growth, likely through direct suppression of tumor glucose metabolism. However, the lack of an effect of dapagliflozin at pharmacologically relevant concentrations suggests that most if not all of the impact of this agent occurs through alterations in systemic metabolism. In contrast, insulin-at doses that are supraphysiologic but commonly used in in vitro studies in the literature-promoted both glucose uptake and oxidation in E0771 tumors, accelerating tumor cell division (Fig. 2a-c).

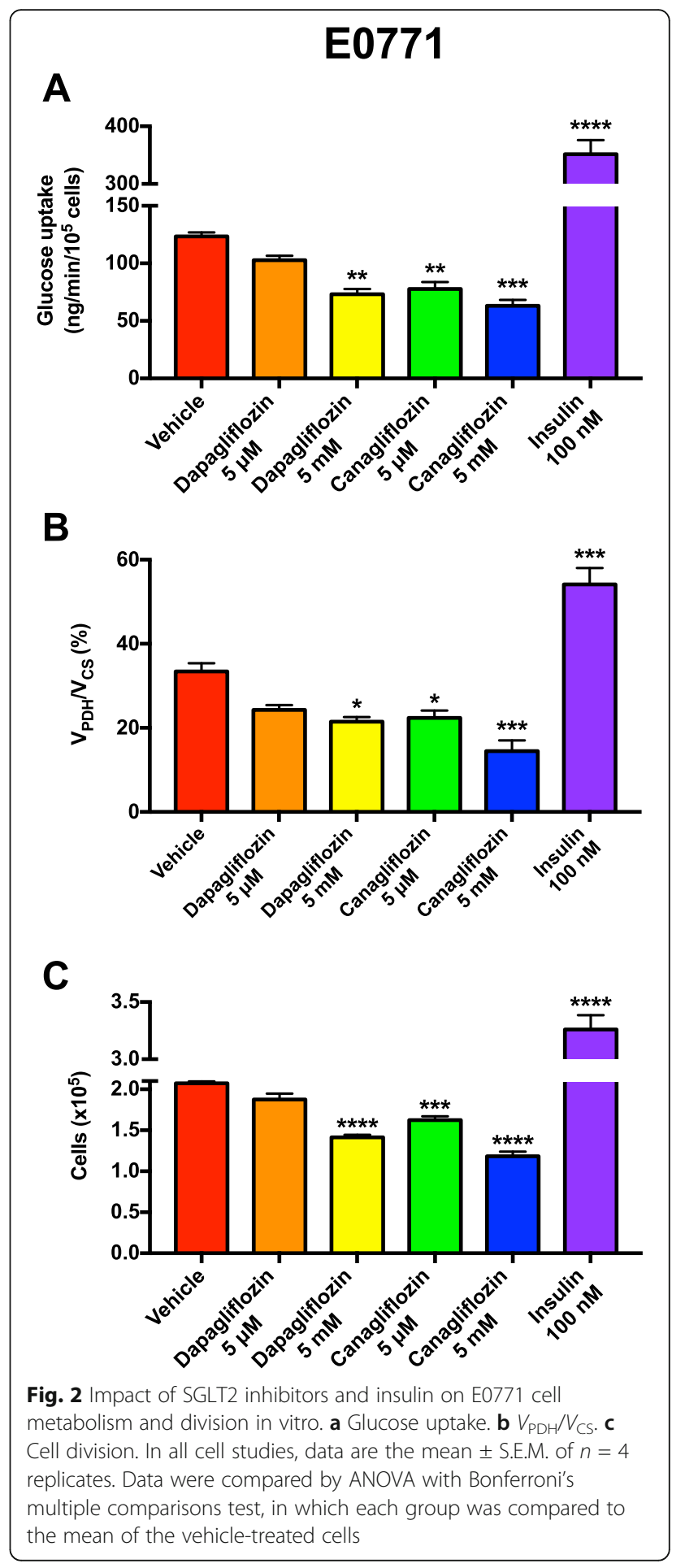

CRMP slows E0771 tumor growth in obese mice in an insulin-dependent manner

After observing the ability of dapagliflozin to slow E0771 breast tumor growth by reversing hyperinsulinemia, we asked whether similar effects would be seen as a result of reducing circulating insulin concentrations with an agent that works through a divergent mechanism. To 
that end, we treated obese, HFD fed, E0771 tumorbearing mice with CRMP. Consistent with previous data $[34,56]$ and with an uncoupling effect confined to the liver, CRMP treatment did not alter body weight or fat mass, whole-body energy expenditure, food or water intake, or respiratory exchange ratio in obese mice (Additional file 1: Figure S2A-J). However, mitochondrial uncoupling lowered liver, plasma, and skeletal muscle triglyceride content (Fig. 3a, Additional file 1: Figure S2K-L). This reduction in ectopic lipid content resulted in lower 5-h fasted plasma glucose concentrations, and lower plasma insulin concentrations under both fed and fasted conditions (Fig. 3b, c). Tumor glucose uptake and oxidation were both modulated by circulating insulin concentrations and normalized by insulin sensitization: high fat feeding increased, and CRMP decreased, both parameters. However, restoring hyperinsulinemia by chronic subcutaneous insulin infusion increased tumor glucose uptake and oxidation to levels measured in untreated HFD tumor-bearing mice, confirming that tumor

\section{E0771}

A

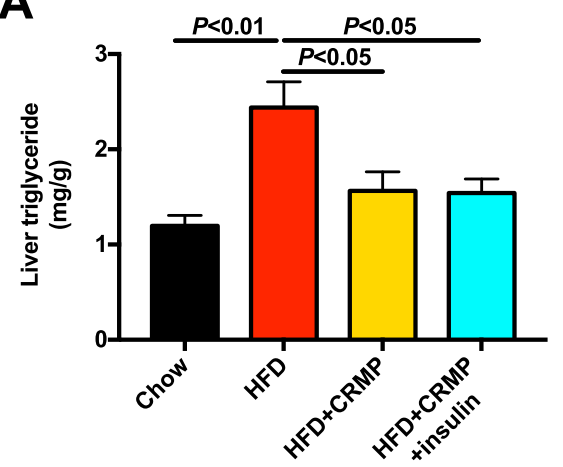

B

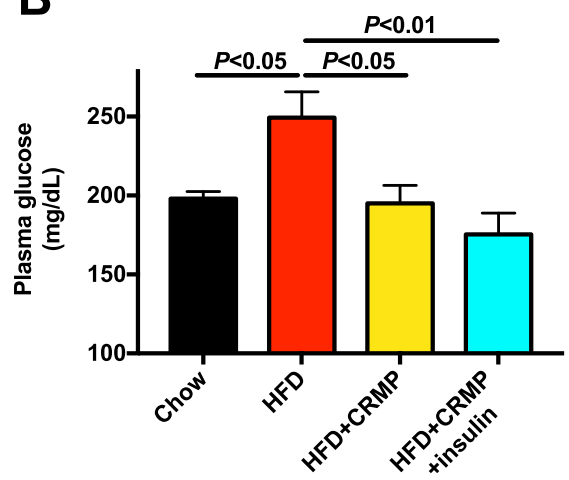

C

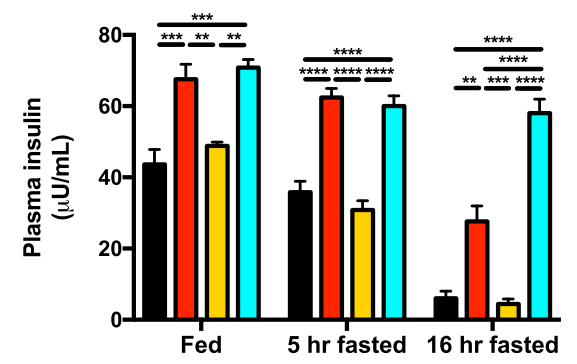

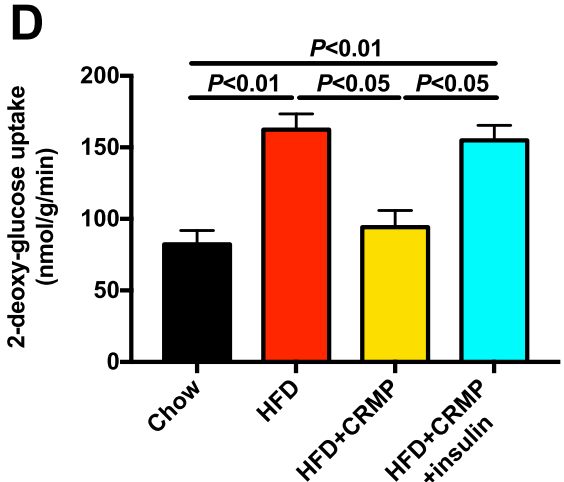

E

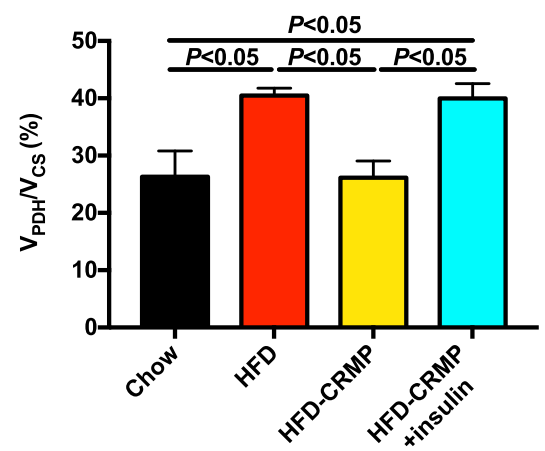

$\mathbf{F}$

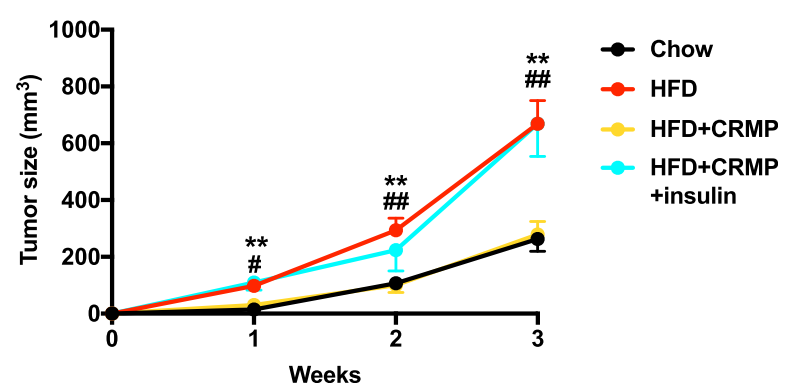

Fig. 3 A controlled-release mitochondrial protonophore slows E0771 breast tumor growth in an insulin-dependent manner. a Liver triglyceride content. In all panels, unless otherwise specified, all mice were fasted for $5 \mathrm{~h}$ before they were studied. b, c Plasma glucose and insulin concentrations. d Tumor 2-deoxyglucose uptake and $V_{\mathrm{PDH}} / V_{\mathrm{CS}}$. f Tumor size. ${ }^{* *} P<0.01 \mathrm{vs}$. chow, $\# P<0.05$, \#\#P<0.01 vs. HFD $+\mathrm{CRMP}$, with the color of the symbols indicating the group compared to the group designated by the symbols. In all panels, data are the mean \pm S.E.M. of $n=5-$ 6 per group. Groups were compared by ANOVA with Bonferroni's multiple comparisons test 
glucose uptake and oxidation are dynamic and insulinresponsive (Fig. 3d, e). These insulin-mediated alterations in tumor glucose metabolism translated to differences in tumor size: high fat feeding accelerated E0771 tumor growth, whereas the reversal of insulin resistance and hyperinsulinemia with CRMP reversed this effect through an insulin-mediated mechanism. However, infusion of insulin via subcutaneous pellet to match plasma insulin concentrations in CRMP-treated mice to those of HFD control animals completely abrogated the effect of CRMP to slow tumor growth (Fig. 3f).

Next, we aimed to understand whether DNP exerted a direct effect on tumor growth or metabolism independent of insulin. Although tumor DNP concentrations in six CRMP-treated mouse tumors were negligible $(0.015$ $\pm 0.003 \mathrm{nmol} / \mathrm{g}$, approximately equivalent to $0.015 \mu \mathrm{M}$ ), we confirmed that DNP did not affect tumor glucose metabolism or growth directly by measuring the rate of glucose uptake, $V_{\mathrm{PDH}} / V_{\mathrm{CS}}$, and cell division in vitro in MC38 cells and found each parameter to be unaltered after incubation in $1 \mu \mathrm{M}$ DNP but increased with high concentrations of insulin (Fig. 4a-c). However, higher, markedly supraphamacologic DNP concentrations were toxic to the cells, reducing tumor glucose uptake, oxidation, and cell number.

\section{Dapagliflozin slows MC38 tumor growth in obese mice in} an insulin-dependent manner

Having demonstrated that dapagliflozin impedes E0771 tumor growth by reversing systemic hyperinsulinemia, we next asked whether these results would translate to a second obesity-associated mouse tumor model: MC38 colon adenocarcinoma. Dapagliflozin caused profound glucosuria and increased water drinking before divergence in body weight, but did not affect food intake, energy expenditure, or the respiratory exchange ratio (Additional file 1: Figure S3A-J). However, after 4 weeks of treatment, dapagliflozin treatment resulted in lower body weight, an effect partially abrogated by insulin replacement (Additional file 1: Figure S3K-L). Chronic dapagliflozin treatment lowered plasma glucose and insulin concentrations and reduced both tumor glucose uptake and $V_{\mathrm{PDH}} / V_{\mathrm{CS}}$ in an insulin-dependent manner, whereas obesity increased tumor glucose metabolism and SGLT2 inhibition normalized it, the obesity- and hyperinsulinemia-associated increases in glucose uptake and oxidation were restored by chronic subcutaneous insulin infusion (Fig. 5b-e). Similar to its effect in E0771 breast cancer, dapagliflozin slowed MC38 tumor growth: 4 weeks after tumor implantation, tumor size was reduced by $50 \%$ in dapagliflozin-treated obese mice; however, the effect of dapagliflozin to slow tumor growth was reversed by restoring hyperinsulinemia (Fig. 5f).

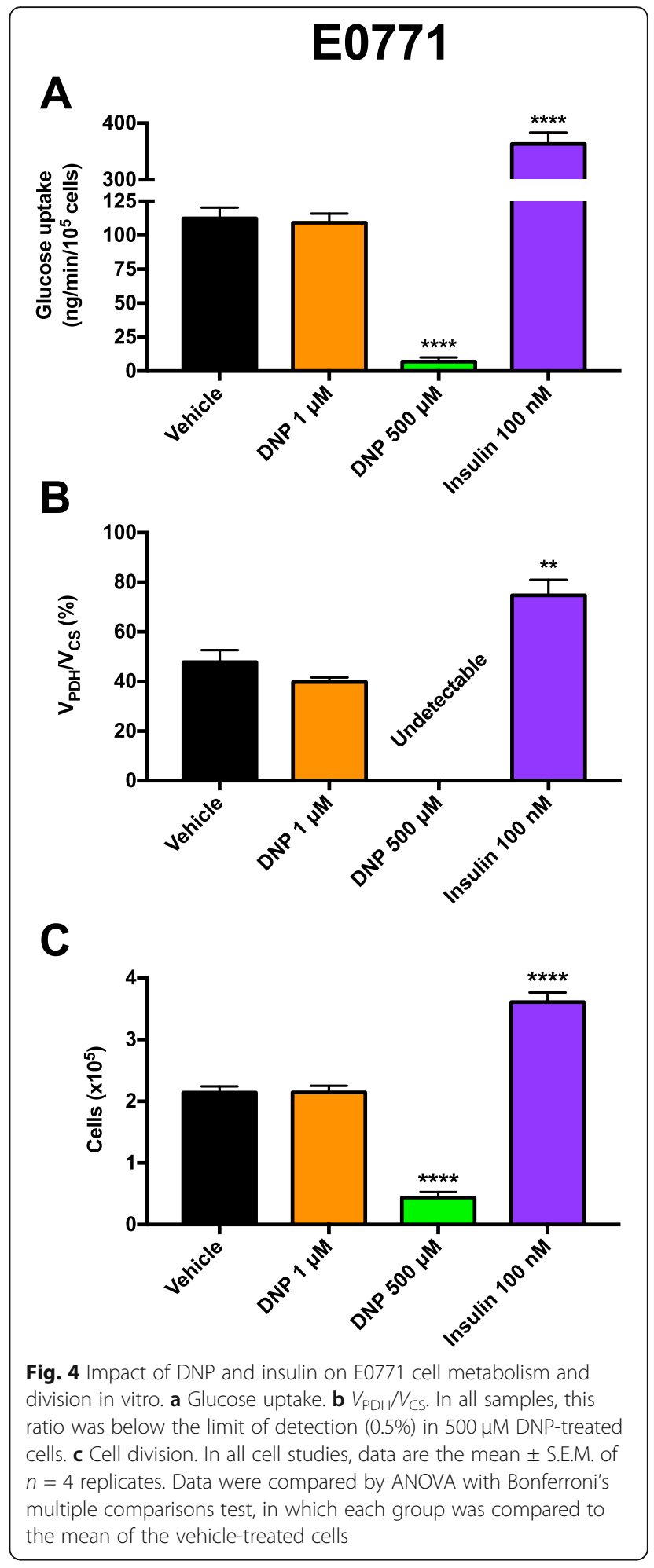

Next, we explored whether SGLT2 inhibitors exert a direct effect to alter glucose metabolism or cell division in MC38 cells at pharmacologically relevant concentrations. While dapagliflozin did not alter glucose uptake, $V_{\mathrm{PDH}} / V_{\mathrm{CS}}$, or cell division at concentrations in the range 


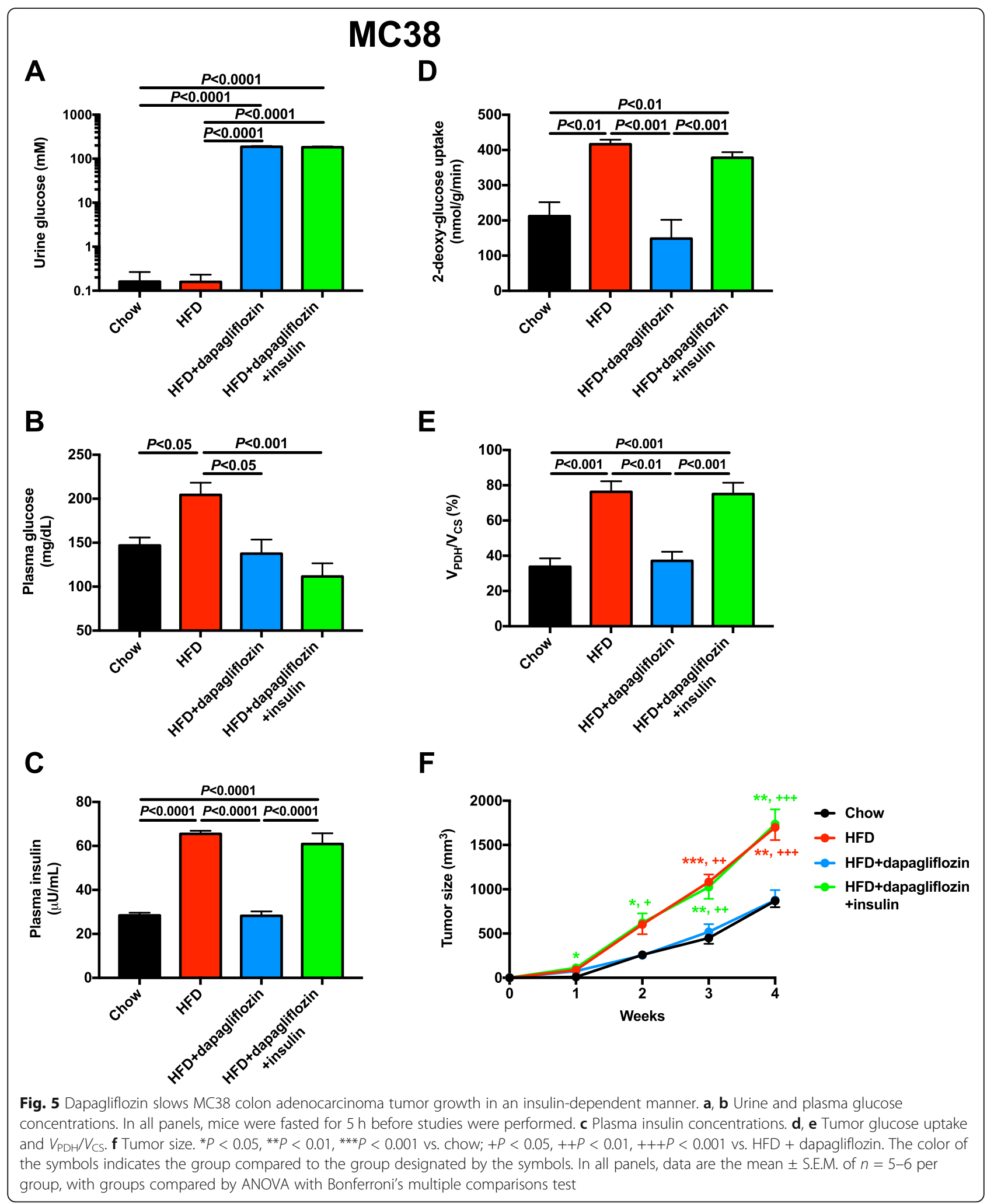

of those measured in patients treated with the maximum daily dose of the drug $(0.5 \mu \mathrm{M})$, but reduced all three parameters at a suprapharmacologic concentration (5
$\mathrm{mM}$ ), canagliflozin reduced both glucose uptake and oxidation at pharmacologically relevant concentrations (Fig. 6a-c). Because SGLT2 inhibitors can cause 


\section{MC38}

A

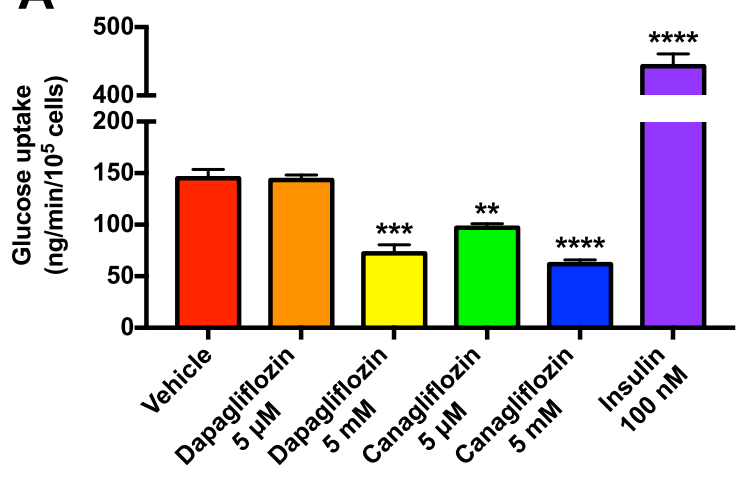

B

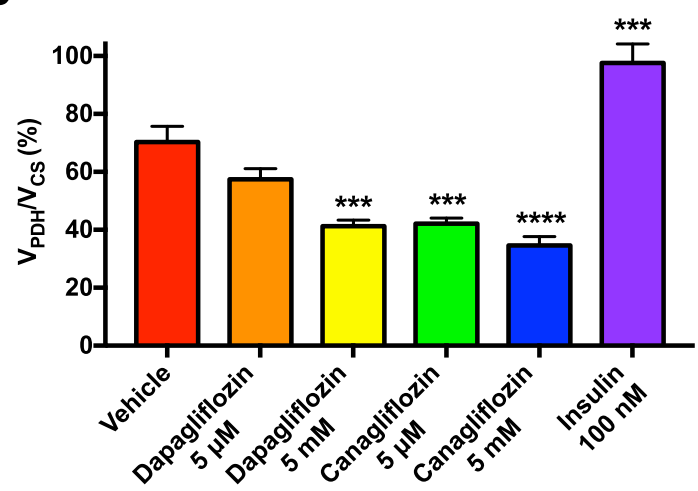

C

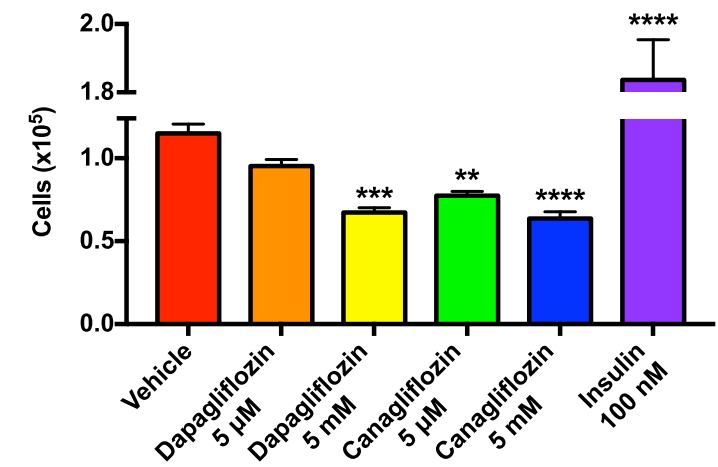

D

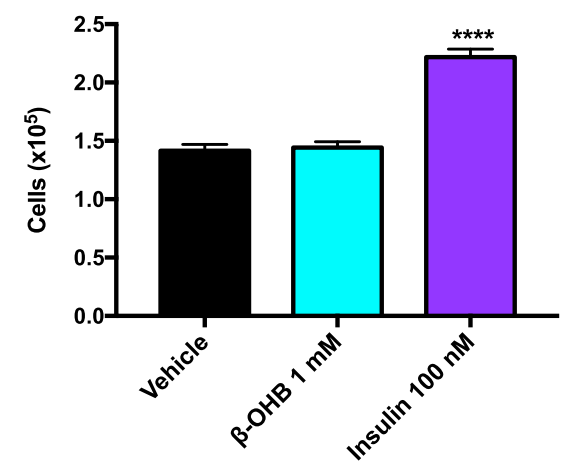

E

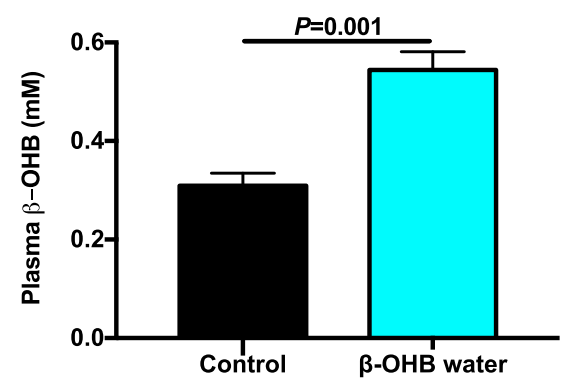

$\mathbf{F}$

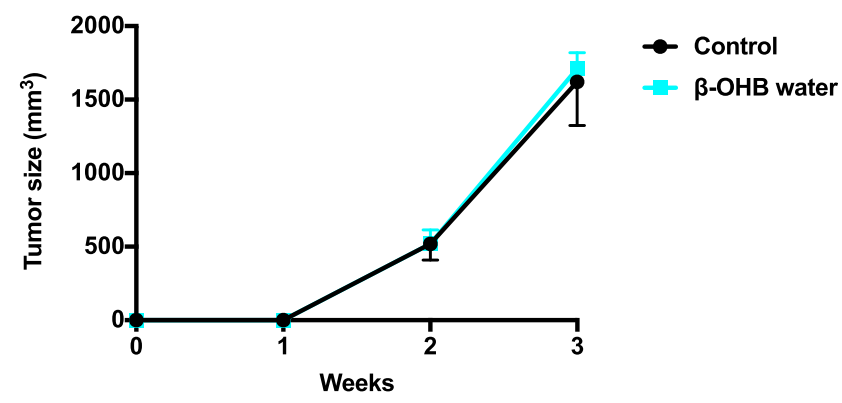

Fig. 6 Neither SGLT2 inhibitors nor $\beta-O H B$ directly alter MC38 tumor cell division. a Impact of SGLT2 inhibitors and insulin on MC38 cell glucose uptake in vitro. In panels $\mathbf{a}-\mathbf{d}, n=4$ in vitro replicates, with groups compared by ANOVA with Bonferroni's multiple comparisons test, in which each group was compared to the vehicle-treated cells $\left.{ }^{* *} P<0.01,{ }^{* * *} P<0.001,{ }^{* * *} P<0.0001\right)$. b $V_{\text {PDH }} / V_{C S}$. c Cell division. d Impact of $\beta-O H B$ and insulin on cell division. e Plasma $\beta-\mathrm{OHB}$ concentrations after 4 weeks of $\beta-\mathrm{OHB}$ supplementation in drinking water, which was removed $2 \mathrm{~h}$ before plasma was obtained. f Tumor size. In panels e and $\mathbf{f}, n=8$ per group, with groups compared by the two-tailed unpaired Student's $t$ test. All data are presented as the mean \pm S.E.M

ketoacidosis [57], albeit typically not in the wellhydrated state [58], and a ketogenic diet may slow tumor growth, at least in animals [59], we then asked whether ketones themselves may alter tumor growth. In contrast to insulin, which promoted MC38 cell division in vitro at supraphysiologic concentrations, incubation in physiologic $(1 \mathrm{mM})$ concentrations of $\beta$-hydroxybutyrate $(\beta-\mathrm{OHB})$ had no impact on cell division (Fig. $6 \mathrm{~d})$. Finally, we examined the potential impact of ketones themselves to alter MC38 tumor growth in vivo and found that chronic (4 weeks) ketone supplementation in drinking water had no impact on plasma glucose or insulin 
concentrations or on tumor size, despite doubling plasma $\beta$-OHB concentrations (Fig. 6e, f, Additional file 1: Figure $\mathrm{S} 3 \mathrm{M}-\mathrm{N})$.

Tumor insulin signaling changes dynamically after a meal The fact that insulin promotes tumor growth in vivo, associated with increased tumor glucose uptake and oxidation, and that two agents that lower both fasting and postprandial insulin concentrations strikingly slow both E0771 and MC38 tumor growth, suggest that tumor insulin signaling may be dynamically regulated. To test this possibility, we performed an oral glucose tolerance test in MC38 tumor-bearing mice and observed a transient postprandial increase in phosphorylation of Akt in tumor (pSer473), which was slightly delayed as compared to plasma insulin concentrations, and an increase in tumor pThr389 p70 S6K (Fig. 7a, b, Additional file 1: Figure S5A-B), demonstrating that tumor insulin signaling indeed is acutely altered in response to normal physiological changes in insulin concentrations.

\section{Discussion}

Obesity increases the risk of certain tumor types, and intentional weight loss may mitigate cancer risk [60, 61]; however, because weight loss is difficult to achieve and even more difficult to maintain, and may not be advisable in certain patients with cancer, alternative approaches-and inquiry into the mechanisms by which obesity-associated cancer risk may be reduced-are urgently warranted. Metformin has been shown to slow both breast [62] and colon cancer [63] in multiple preclinical models, but results in humans are mixed and clear evidence for a large anti-tumor effect of metformin are lacking. Metformin's underwhelming efficacy may be due in part to its mechanism: the drug inhibits gluconeogenesis but does not exert an insulin-sensitizing effect; therefore, it lowers fasting plasma glucose and insulin concentrations but has a much smaller effect on these parameters under postprandial conditions (Additional file 1: Figure S1M). In the current study, we demonstrate that tumor insulin signaling is dynamically regulated under postprandial conditions (Fig. 7). These data suggest that agents that lower both fasting and postprandial insulin concentrations, whether by urinary glucose wasting (Fig. 1a,c, and Fig. 5a,c) or by insulin sensitization (Fig. 3c) would be more effective because they would have a more profound impact on total insulin area under the curve throughout the day.

For this reason, in the current study, we investigated the impact of two agents that lower plasma insulin concentrations under both fed and fasted conditions, CRMP and dapagliflozin, in two mouse models of obesityassociated cancer. Previous studies have reported conflicting results regarding the interaction between SGLT2

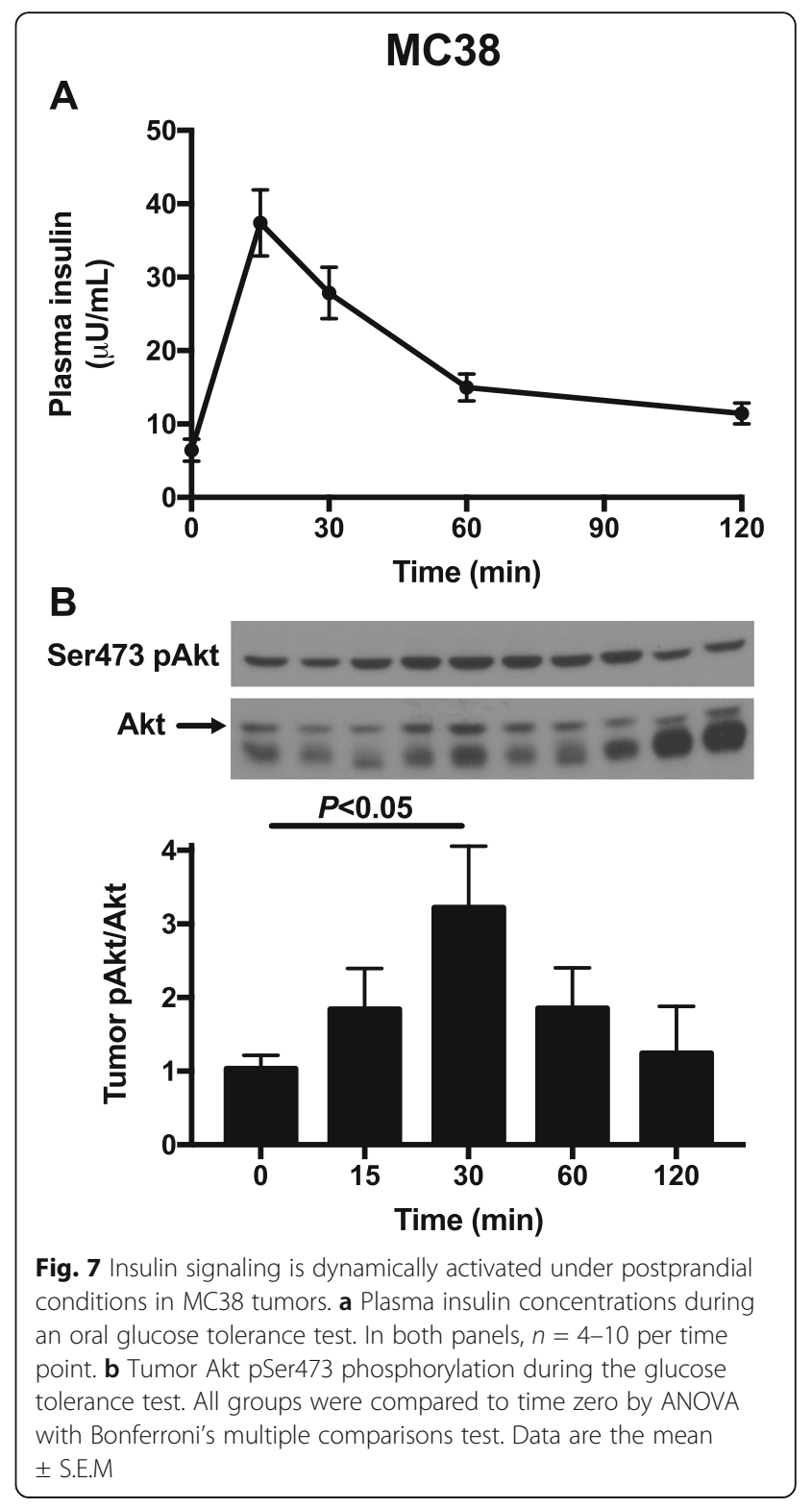

inhibitors and cancer risk: a slightly—not statistically significantly-elevated risk of bladder cancer in men and of breast cancer in women was initially reported; however, this has since been attributed to detection bias, as both animal studies using higher doses and better-powered human studies have not detected an increased risk of cancer in those treated with SGLT2 inhibitors [64]. To the contrary, recent in vivo studies have suggested that SGLT2 inhibition may be an effective means of attenuating hepatocellular [44-46], renal cell [43], and lung cancer [47] growth by an unclear mechanism.

Based on the insulin-dependent impact of a mitochondrial uncoupler to slow obesity-associated colon cancer growth in mouse models [35], we hypothesized that the SGLT2 inhibitor dapagliflozin, which lowers both fasting 
and postprandial glucose and insulin concentrations, may slow obesity-associated breast and colon tumor growth through an insulin-dependent mechanism. Consistent with this hypothesis, dapagliflozin slowed tumor growth in mouse models of obesity-associated breast and colon cancer; however, the ability of dapagliflozin to slow tumor growth was completely abrogated by subcutaneous insulin infusion to increase plasma insulin concentrations to those measured in HFD controls. While suprapharmacologic concentrations of two SGLT2 inhibitors did reduce E0771 and MC38 tumor cell division in a cellautonomous manner, this effect was correlated with reductions in glucose uptake and oxidation in vitro-again demonstrating the key role for dynamic regulation of tumor glucose uptake-and is likely of minimal relevance in vivo; otherwise, dapagliflozin would be expected to slow tumor growth independent of insulin replacement. Importantly, an insulin-dependent or insulin-independent effect on tumor glycolysis and/or lactate metabolism cannot be ruled out in these studies: it is possible that insulindependent changes in tumor cell glucose oxidation combine with alterations in glycolytic metabolism to mediate the effects observed on tumor growth in vivo.

Having demonstrated that dapagliflozin slows tumor growth in two mouse models of obesity-associated cancer and that reversal of hyperinsulinemia is necessary for the in vivo tumor-suppressive effect of this SGLT2 inhibitor, we then examined a second insulin-lowering agent, CRMP, which works by an entirely independent mechanism: insulin sensitization [34], rather than calorie loss through glycosuria. CRMP reversed NAFLD and normalized muscle lipid content, likely through reductions in hepatic lipid export, as we have previously demonstrated [34]. Like dapagliflozin, incubation in DNP, the active agent in CRMP, had no impact on tumor cell division in vitro. Combined with in vivo data demonstrating that increasing plasma insulin concentrations in CRMP-treated mice to match those measured in HFD controls renders CRMP unable to slow tumor progression, these data demonstrate that the ability of this insulin sensitizer to slow E0771 breast tumor growth depends on its effect to reverse hyperinsulinemia. In addition, changes in body weight and body fat were dissociated from the effect of CRMP on tumor growth: CRMP treatment was not associated with any difference in either parameter, despite its striking effect to slow tumor growth.

\section{Conclusions}

In summary, these data demonstrate that strategies to mitigate hyperinsulinemia-preferably both fasting and postprandial hyperinsulinemia, as can be accomplished using SGLT2 inhibitors, which are already in the clinic, or insulin sensitizers under development-may be therapeutic targets worthy of further exploration to attenuate breast and/or colon cancer risk and progression. These results are consistent with clinical data indicating that exercise and weight loss, which are classic insulin sensitizing interventions, attenuate the risk and slow the progression of breast cancer $[60,65,66]$ and may also slow the progression of colon cancer [67-69]. However, because weight loss after cancer diagnosis is associated with poorer outcomes, interventions that cause little to no weight loss but reduce insulin concentrations out of proportion to body weight change may be attractive targets. Taken together, these data demonstrate that hyperinsulinemia per se promotes breast cancer progression in obese mice, and recommend clinical studies investigating the potential utility of insulin-lowering agents including SGLT2 inhibitors and insulin-sensitizing mitochondrial protonophores currently under development as a means of slowing obesity-associated breast tumor growth.

\section{Supplementary information}

Supplementary information accompanies this paper at https://doi.org/10. 1186/s40170-019-0203-1.

Additional file 1: Figure S1. Dapagliflozin slows E0771 breast tumor growth in an insulin-dependent manner. Figure S2. A controlled-release mitochondrial protonophore slows E0771 breast tumor growth in an insulin-dependent manner. Figure S3. Dapagliflozin slows MC38 colon tumor growth in an insulin-dependent manner. Figure S4. Ketone supplementation in drinking water does not independently alter MC38 colon tumor growth. Figure S5. Insulin signaling is dynamically activated under postprandial conditions in MC38 tumors.

\section{Abbreviations}

CRMP: Controlled-release mitochondrial protonophore; NAFLD: Non-alcoholic fatty liver disease; SGLT2: Sodium-glucose cotransporter-2

\section{Acknowledgements \\ The authors thank Wanling Zhu and Xiaoxian Ma for their expert technical assistance in the in vivo infusion studies; Xian-Man Zhang, Gina Butrico, and John Stack for their invaluable technical assistance with mass spectrometry analysis; and Maria Batsu and Codruta Teasa in the Yale Diabetes Research Center for performing insulin RIAs.}

\section{Authors' contributions}

The study was designed and the first draft of the manuscript was written by RJP. Studies were performed and data analyzed by ARN, MRR, ZL, BPL, and RJP. All authors edited and approved the final version of the manuscript.

\section{Funding}

This study was supported by grants from the U.S. Public Health Service (K99/ R00 CA-215315, P50 CA121974-11A1, CTSA UL1TR000142, P30 DK045735, Medical Scientist Training Program Training Grant T32 GM007205), and by a Yale Cancer Center Innovation Award.

\section{Availability of data and materials}

The data generated in this study are available from the corresponding author upon reasonable request.

Ethics approval and consent to participate

All animal studies were approved by the Yale University Institutional Animal Care and Use Committee. 


\section{Consent for publication}

Not applicable.

\section{Competing interests}

RJP holds investigator-initiated support from AstraZeneca for a project unrelated to cancer, examining the mechanism by which SGLT2 inhibitors may predispose to euglycemic ketoacidosis in rats, and is a co-inventor on a patent application filed by Yale University for mitochondrial uncoupling agents, including CRMP, for NAFLD. All other authors declare that they have no competing interests.

\section{Author details}

'Department of Internal Medicine, School of Medicine, Yale University, PO Box 208020, TAC S269, New Haven, CT 06520, USA. ²Department of Cellular \& Molecular Physiology, School of Medicine Yale University, PO Box 208020, TAC S269, New Haven, CT 06520, USA. ${ }^{3}$ Department of Surgery, State University of Ponta Grossa, Ponta Grossa, Brazil.

\section{Received: 9 September 2019 Accepted: 20 November 2019}

\section{Published online: 11 December 2019}

\section{References}

1. Islami F, Goding Sauer A, Gapstur SM, Jemal A. Proportion of cancer cases attributable to excess body weight by US state, 2011-2015. JAMA Oncol. :2018.

2. Allott EH, Hursting SD. Obesity and cancer: mechanistic insights from transdisciplinary studies. Endocr Relat Cancer. 2015;22(6):R365-86.

3. Jiralerspong S, Goodwin PJ. Obesity and breast cancer prognosis: evidence, challenges, and opportunities. J Clin Oncol. 2016;34(35):4203-16.

4. Sung MK, Yeon JY, Park SY, Park JH, Choi MS. Obesity-induced metabolic stresses in breast and colon cancer. Ann N Y Acad Sci. 2011;1229:61-8.

5. Tarasiuk A, Mosinska P, Fichna J. The mechanisms linking obesity to colon cancer: an overview. Obes Res Clin Pract. 2018;12(3):251-9.

6. Rabin-Court A, Rodrigues MR, Zhang XM, Perry RJ. Obesity-associated, but not obesity-independent, tumors respond to insulin by increasing mitochondrial glucose oxidation. PLoS One. 2019:14(6):e0218126.

7. Chen X, Liang H, Song Q, Xu X, Cao D. Insulin promotes progression of colon cancer by upregulation of ACAT1. Lipids Health Dis. 2018;17(1):122.

8. Belfiore A, Frittitta L, Costantino A, Frasca F, Pandini G, Sciacca L, et al Insulin receptors in breast cancer. Ann N Y Acad Sci. 1996;784:173-88.

9. Gupta C, Tikoo K. High glucose and insulin differentially modulates proliferation in MCF-7 and MDA-MB-231 cells. J Mol Endocrinol. 2013;51(1): 119-29.

10. Gross GE, Boldt DH, Osborne CK. Perturbation by insulin of human breast cancer cell cycle kinetics. Cancer Res. 1984;44(8):3570-5.

11. Gunter MJ, Hoover DR, Yu H, Wassertheil-Smoller S, Rohan TE, Manson JE, et al. Insulin, insulin-like growth factor-I, and risk of breast cancer in postmenopausal women. J Natl Cancer Inst. 2009;101(1):48-60.

12. Kabat GC, Kim M, Caan BJ, Chlebowski RT, Gunter MJ, Ho GY, et al. Repeated measures of serum glucose and insulin in relation to postmenopausal breast cancer. Int J Cancer. 2009;125(11):2704-10.

13. Shu X, Wu L, Khankari NK, Shu XO, Wang TJ, Michailidou K, et al. Associations of obesity and circulating insulin and glucose with breast cancer risk: a Mendelian randomization analysis. Int J Epidemiol. 2018.

14. Kabat GC, Kim MY, Lane DS, Zaslavsky O, Ho GYF, Luo J, et al. Serum glucose and insulin and risk of cancers of the breast, endometrium, and ovary in postmenopausal women. Eur J Cancer Prev. 2018;27(3):261-8.

15. Lawlor DA, Smith GD, Ebrahim S. Hyperinsulinaemia and increased risk of breast cancer: findings from the British Women's Heart and Health Study. Cancer Causes Control. 2004;15(3):267-75.

16. Schoen RE, Tangen CM, Kuller LH, Burke GL, Cushman M, Tracy RP, et al. Increased blood glucose and insulin, body size, and incident colorectal cancer. J Natl Cancer Inst. 1999:91(13):1147-54.

17. Kaaks R, Toniolo P, Akhmedkhanov A, Lukanova A, Biessy C, Dechaud H, et al. Serum C-peptide, insulin-like growth factor (IGF)-I, IGF-binding proteins, and colorectal cancer risk in women. J Natl Cancer Inst. 2000; 92(19):1592-600.

18. Ma J, Giovannucci E, Pollak M, Leavitt A, Tao Y, Gaziano JM, et al. A prospective study of plasma C-peptide and colorectal cancer risk in men. J Natl Cancer Inst. 2004;96(7):546-53.
19. $\mathrm{Xu} \mathrm{J}, \mathrm{Ye} Y$, Wu H, Duerksen-Hughes $P$, Zhang $H$, Li P, et al. Association between markers of glucose metabolism and risk of colorectal cancer. BMJ Open. 2016;6(6):e011430

20. Peeters PJ, Bazelier MT, Leufkens HG, de Vries F, De Bruin ML. The risk of colorectal cancer in patients with type 2 diabetes: associations with treatment stage and obesity. Diabetes Care. 2015;38(3):495-502.

21. Gallagher EJ, Fierz Y, Vijayakumar A, Haddad N, Yakar S, LeRoith D. Inhibiting PI3K reduces mammary tumor growth and induces hyperglycemia in a mouse model of insulin resistance and hyperinsulinemia. Oncogene. 2012 31(27):3213-22.

22. Gallagher EJ, Alikhani N, Tobin-Hess A, Blank J, Buffin NJ, Zelenko Z, et al. Insulin receptor phosphorylation by endogenous insulin or the insulin analog AspB10 promotes mammary tumor growth independent of the IGF-I receptor. Diabetes. 2013;62(10):3553-60

23. Hopkins BD, Pauli C, Du X, Wang DG, Li X, Wu D, et al. Suppression of insulin feedback enhances the efficacy of PI3K inhibitors. Nature. 2018; 560(7719):499-503.

24. Gallagher EJ, Zelenko Z, Tobin-Hess A, Werner U, Tennagels N, LeRoith D. Non-metabolisable insulin glargine does not promote breast cancer growth in a mouse model of type 2 diabetes. Diabetologia. 2016;59(9):2018-25.

25. Wu JW, Azoulay L, Majdan A, Boivin JF, Pollak M, Suissa S. Long-term use of long-acting insulin analogs and breast cancer incidence in women with type 2 diabetes. J Clin Oncol. 2017;35(32):3647-53.

26. Tseng $\mathrm{CH}$. Prolonged use of human insulin increases breast cancer risk in Taiwanese women with type 2 diabetes. BMC Cancer. 2015;15:846.

27. Karlstad O, Starup-Linde J, Vestergaard P, Hjellvik V, Bazelier MT, Schmidt MK, et al. Use of insulin and insulin analogs and risk of cancer - systematic review and meta-analysis of observational studies. Curr Drug Saf. 2013;8(5):333-48.

28. Chen L, Chubak J, Boudreau DM, Barlow WE, Weiss NS, Li Cl. Diabetes treatments and risks of adverse breast cancer outcomes among early-stage breast cancer patients: a SEER-Medicare Analysis. Cancer Res. 2017;77(21): 6033-41.

29. Sonnenblick A, Agbor-Tarh D, Bradbury I, Di Cosimo S, Azim HA Jr, Fumagalli $D$, et al. Impact of diabetes, insulin, and metformin use on the outcome of patients with human epidermal growth factor receptor 2positive primary breast cancer: analysis from the ALTTO Phase III Randomized Trial. J Clin Oncol. 2017;35(13):1421-9.

30. Tseng $\mathrm{CH}$. Use of insulin and mortality from breast cancer among Taiwanese women with diabetes. J Diabetes Res. 2015;2015:678756.

31. Bronsveld HK, ter Braak B, Karlstad O, Vestergaard P, Starup-Linde J, Bazelier $M T$, et al. Treatment with insulin (analogues) and breast cancer risk in diabetics; a systematic review and meta-analysis of in vitro, animal and human evidence. Breast Cancer Res. 2015:17:100.

32. Peeters PJ, Bazelier MT, Leufkens HG, Auvinen A, van Staa TP, de Vries F, et al. Insulin glargine use and breast cancer risk: associations with cumulative exposure. Acta Oncol. 2016;55(7):851-8.

33. Bordeleau L, Yakubovich N, Dagenais GR, Rosenstock J, Probstfield J, Chang Yu P, et al. The association of basal insulin glargine and/or n-3 fatty acids with incident cancers in patients with dysglycemia. Diabetes Care. 2014; 37(5):1360-6.

34. Perry RJ, Zhang D, Zhang XM, Boyer JL, Shulman Gl. Controlled-release mitochondrial protonophore reverses diabetes and steatohepatitis in rats. Science. 2015:347(6227):1253-6.

35. Wang Y, Nasiri AR, Damsky WE, Perry CJ, Zhang XM, Rabin-Court A, et al. Uncoupling hepatic oxidative phosphorylation reduces tumor growth in two murine models of colon cancer. Cell Rep. 2018;24(1):47-55.

36. Algire C, Amrein L, Zakikhani M, Panasci L, Pollak M. Metformin blocks the stimulative effect of a high-energy diet on colon carcinoma growth in vivo and is associated with reduced expression of fatty acid synthase. Endocr Relat Cancer. 2010;17(2):351-60.

37. Shaw RJ, Lamia KA, Vasquez D, Koo SH, Bardeesy N, Depinho RA, et al. The kinase LKB1 mediates glucose homeostasis in liver and therapeutic effects of metformin. Science. 2005;310(5754):1642-6.

38. Chung EJ, Do EJ, Kim SY, Cho EA, Kim DH, Pak S, et al. Combination of metformin and VSL\#3 additively suppresses western-style diet induced colon cancer in mice. Eur J Pharmacol. 2016;794:1-7.

39. Nie Z, Zhu H, Gu M. Reduced colorectal cancer incidence in type 2 diabetic patients treated with metformin: a meta-analysis. Pharm Biol. 2016;54(11): 2636-42.

40. Rokkas T, Portincasa P. Colon neoplasia in patients with type 2 diabetes on metformin: a meta-analysis. Eur J Intern Med. 2016;33:60-6. 
41. Komatsu S, Nomiyama T, Numata T, Kawanami T, Hamaguchi Y, Tanaka T, et al. SGLT2 inhibitor ipragliflozin induces breast cancer apoptosis via membrane hyperpolarization and mitochondria dysfunction. Diabetes. 2018;67(Jul).

42. Ware K, Smith T, Brown D, Hill D, Stewart L. The effect of sodium glucose transporter 2 inhibitors on proliferation and growth factor signaling pathways in triple negative breast cancer. FASEB J. 2019;33(1).

43. Kuang H, Liao L, Chen H, Kang Q, Shu X, Wang Y. Therapeutic effect of sodium glucose co-transporter 2 inhibitor dapagliflozin on renal cell carcinoma. Med Sci Monit. 2017;23:3737-45.

44. Kaji K, Nishimura N, Seki K, Sato S, Saikawa S, Nakanishi K, et al. Sodium glucose cotransporter 2 inhibitor canagliflozin attenuates liver cancer cell growth and angiogenic activity by inhibiting glucose uptake. Int J Cancer. 2018;142(8):1712-22.

45. Shiba K, Tsuchiya K, Komiya C, Miyachi Y, Mori K, Shimazu N, et al. Canagliflozin, an SGLT2 inhibitor, attenuates the development of hepatocellular carcinoma in a mouse model of human NASH. Sci Rep. 2018; 8(1):2362.

46. Obara K, Shirakami Y, Maruta A, Ideta T, Miyazaki T, Kochi T, et al. Preventive effects of the sodium glucose cotransporter 2 inhibitor tofogliflozin on diethylnitrosamine-induced liver tumorigenesis in obese and diabetic mice. Oncotarget. 2017:8(35):58353-63.

47. Scafoglio CR, Villegas B, Abdelhady G, Bailey ST, Liu J, Shirali AS, et al. Sodium-glucose transporter 2 is a diagnostic and therapeutic target for early-stage lung adenocarcinoma. Sci Transl Med. 2018;10(467).

48. Mashhedi H, Blouin MJ, Zakikhani M, David S, Zhao Y, Bazile M, et al. Metformin abolishes increased tumor (18)F-2-fluoro-2-deoxy-D-glucose uptake associated with a high energy diet. Cell Cycle. 2011;10(16):2770-8.

49. Fuentes-Mattei E, Velazquez-Torres G, Phan L, Zhang F, Chou PC, Shin JH, et al. Effects of obesity on transcriptomic changes and cancer hallmarks in estrogen receptor-positive breast cancer. J Natl Cancer Inst. 2014;106(7).

50. Camporez JP, Jornayvaz FR, Lee HY, Kanda S, Guigni BA, Kahn M, et al. Cellular mechanism by which estradiol protects female ovariectomized mice from high-fat diet-induced hepatic and muscle insulin resistance. Endocrinology. 2013;154(3):1021-8.

51. Camporez JP, Lyu K, Goldberg EL, Zhang D, Cline GW, Jurczak MJ, et al. Anti-inflammatory effects of estrogen mediate the sexual dimorphic response to Lipid-induced insulin resistance. J Physiol. 2019.

52. Perry RJ, Peng L, Abulizi A, Kennedy L, Cline GW, Shulman Gl. Mechanism for leptin's acute insulin-independent effect to reverse diabetic ketoacidosis. J Clin Invest. 2017;127(2):657-69.

53. Perry RJ, Kim T, Zhang XM, Lee HY, Pesta D, Popov VB, et al. Reversal of hypertriglyceridemia, fatty liver disease, and insulin resistance by a livertargeted mitochondrial uncoupler. Cell Metab. 2013;18(5):740-8.

54. Kasichayanula S, Liu X, Lacreta F, Griffen SC, Boulton DW. Clinical pharmacokinetics and pharmacodynamics of dapagliflozin, a selective inhibitor of sodium-glucose co-transporter type 2. Clin Pharmacokinet. 2014; 53(1):17-27

55. Devineni D, Curtin CR, Polidori D, Gutierrez MJ, Murphy J, Rusch S, et al. Pharmacokinetics and pharmacodynamics of canagliflozin, a sodium glucose co-transporter 2 inhibitor, in subjects with type 2 diabetes mellitus. J Clin Pharmacol. 2013;53(6):601-10.

56. Abulizi A, Perry RJ, Camporez JPG, Jurczak MJ, Petersen KF, Aspichueta P, et al. A controlled-release mitochondrial protonophore reverses hypertriglyceridemia, nonalcoholic steatohepatitis, and diabetes in lipodystrophic mice. FASEB J. 2017;31(7):2916-24.

57. Fralick M, Schneeweiss S, Patorno E. Risk of diabetic ketoacidosis after initiation of an SGLT2 inhibitor. N Engl J Med. 2017;376(23):2300-2.

58. Perry RJ, Rabin-Court A, Song JD, Cardone RL, Wang Y, Kibbey RG, et al. Dehydration and insulinopenia are necessary and sufficient for euglycemic ketoacidosis in SGLT2 inhibitor-treated rats. Nat Commun. 2019;10(1):548.

59. Klement RJ. Beneficial effects of ketogenic diets for cancer patients: a realist review with focus on evidence and confirmation. Med Oncol. 2017:34(8):132.

60. Hardefeldt PJ, Penninkilampi R, Edirimanne S, Eslick GD. Physical activity and weight loss reduce the risk of breast cancer: a meta-analysis of 139 prospective and retrospective studies. Clin Breast Cancer. 2018;18(4): e601-e12.

61. Afshar S, Kelly SB, Seymour K, Lara J, Woodcock S, Mathers JC. The effects of bariatric surgery on colorectal cancer risk: systematic review and metaanalysis. Obes Surg. 2014;24(10):1793-9.
62. De A, Kuppusamy G. Metformin in breast cancer: preclinical and clinical evidence. Curr Probl Cancer. 2019.

63. Anisimov VN. Metformin for prevention and treatment of colon cancer: a reappraisal of experimental and clinical data. Curr Drug Targets. 2016;17(4):439-46.

64. Lin HW, Tseng CH. A review on the relationship between SGLT2 inhibitors and cancer. Int J Endocrinol. 2014;2014:719578.

65. Chlebowski RT, Luo J, Anderson GL, Barrington W, Reding K, Simon MS, et al. Weight loss and breast cancer incidence in postmenopausal women. Cancer. 2019;125(2):205-12.

66. Pan K, Luo J, Aragaki AK, Chlebowski RT. Weight loss, diet composition and breast cancer incidence and outcome in postmenopausal women. Oncotarget. 2019;10(33):3088-92.

67. Yamaji Y, Okamoto M, Yoshida H, Kawabe T, Wada R, Mitsushima T, et al. The effect of body weight reduction on the incidence of colorectal adenoma. Am J Gastroenterol. 2008;103(8):2061-7.

68. Beeken RJ, Croker H, Heinrich M, Obichere A, Finer N, Murphy N, et al. The impact of diet-induced weight loss on biomarkers for colorectal cancer: an exploratory study (INTERCEPT). Obesity (Silver Spring). 2017;25(Suppl 2):S95S101.

69. Bassett JK, Severi G, English DR, Baglietto L, Krishnan K, Hopper JL, et al. Body size, weight change, and risk of colon cancer. Cancer Epidemiol Biomarkers Prev. 2010;19(11):2978-86.

\section{Publisher's Note}

Springer Nature remains neutral with regard to jurisdictional claims in published maps and institutional affiliations.
Ready to submit your research? Choose BMC and benefit from:

- fast, convenient online submission

- thorough peer review by experienced researchers in your field

- rapid publication on acceptance

- support for research data, including large and complex data types

- gold Open Access which fosters wider collaboration and increased citations

- maximum visibility for your research: over $100 \mathrm{M}$ website views per year

At $\mathrm{BMC}$, research is always in progress.

Learn more biomedcentral.com/submissions 